\title{
Light Intensity Affects Growth, Photosynthetic Capability, and Total Flavonoid Accumulation of Anoectochilus Plants
}

\author{
Zengqiang Ma, Shishang Li, and Meijun Zhang \\ College of Life Science, Capital Normal University, Beijing 100048, China; \\ and Yangtze Delta Region Institute of Tsinghua University, Zhejiang 314100, \\ China
}

\author{
Shihao Jiang \\ Yangtze Delta Region Institute of Tsinghua University, Zhejiang 314100, \\ China
}

\begin{abstract}
Yulan Xiao ${ }^{1}$
College of Life Science, Capital Normal University, No. 105 North Xisanhuan Road, Beijing 100048, China; and Yangtze Delta Region Institute of Tsinghua University, Zhejiang 314100, China
\end{abstract}

Additional index words. Anoectochilus formosanus, chlorophyll concentration, electron transport ratio, light stress, SOD activity, total flavonoid content

\begin{abstract}
Anoectochilus formosanus, a medicinal plant used to treat hypertension, lung disease, and liver disease, was grown to maximize biomass and secondary metabolite production in a controlled environment under four levels of photosynthetic photon flux (PPF), namely, 10, 30, 60, or $90 \mu \mathrm{mol} \cdot \mathrm{m}^{-2} \cdot \mathrm{s}^{-1}$, that is $\mathrm{L}_{10}, \mathrm{~L}_{30}, \mathrm{~L}_{60}$, and $\mathrm{L}_{90}$ treatments, respectively. On Day 45, all growth values were greatest for the $L_{30}$ plants. Dry weight was lowest for the $L_{10}$ plants. Leaf area, stem length, and fresh weight were lowest for the $L_{90}$ plants. The chlorophyll concentration was highest in the $L_{10}$ treatment and decreased with increasing $P P F$. Electron transport ratios of leaves were highest in the $\mathbf{L}_{30}$ treatment and lowest in the $L_{90}$ for the second leaf (counted down from the apex) and in the $L_{10}$ for the third leaf. An increase in light intensity from 10 to $60 \mu \mathrm{mol} \cdot \mathrm{m}^{-2} \cdot \mathrm{s}^{-1}$ increased the superoxide dismutase activity and was associated with an increase in the total flavonoid concentration. The total flavonoid concentration ( $\mathrm{mg} \cdot \mathrm{g}^{-1} \mathrm{DW}$ ) was greatest in the $\mathrm{L}_{60}$ and lowest in the $\mathrm{L}_{90}$. However, the total flavonoid content (mg/plant) was highest in the $L_{30}$ plants as a result of great biomass. The results indicated that $A$. formosanus is a typical shade plant suitable to grow under low light intensity at $P P F$ of 30 to $50 \mu \mathrm{mol} \cdot \mathrm{m}^{-2} \cdot \mathrm{s}^{-1}$ for both growth and production of total flavonoid. A light intensity of $90 \mu \mathrm{mol} \cdot \mathrm{m}^{-2} \cdot \mathrm{s}^{-1}$ induced stress on plant growth and reduced photosynthetic capability and the flavonoid accumulation.
\end{abstract}

Anoectochilus, a perennial herb, belonging to the Orchidaceous family, which comprises more than 35 species that are widespread in the tropical regions, from India through the Himalayas and Southeast Asia to Hawaii (Asahishinbun, 1997). Anoectochilus is a short (10 to $15 \mathrm{~cm}$ in length) and typical shade plant and mainly distributed at an altitude of 400 to $1200 \mathrm{~m}$ of the wet zone. Several species have been used in Chinese medicine. Among

Received for publication 12 Jan. 2010. Accepted for publication 16 Apr. 2010

We are grateful for the financial support provided by the Science and Technology Department of Zhejiang Province (No. 2006C12041) and the Forest Bureau of Yongchun County of Fujian Province, China. We thank Dr. Qichang Yang of The Chinese Academy of Agricultural Science for his kind help and valuable suggestions during the experiment.

${ }^{1}$ To whom reprint requests should be addressed; e-mailylxiao@yahoo.com. them, Anoectochilus formosanus, only found in Taiwan and Okinawa, has been used for hypertension, lung disease, and liver disease and underdeveloped children as a folk remedy (Kan, 1986). One of the most active components in Anoectochilus was flavonoid (Takatsuki et al., 1992). Many of flavonoid constituents have antioxidant properties (Shih et al., 2003).

The international trade of medicinal plants is becoming a major force in the global economy, and the demands of $A$. formosanus are rapidly increasing in Chinese medicine. However, overharvesting wild species is one of the serious issues for plant conservation. In addition, the explosive demand in plant materials for medicinal preparation has been accompanied by issues of quality and consistency, because the natural sources of $A$. formosanus are exhausted and growth of $A$. formosanus in the field has many problems, for instance, small seeds with slow germination rate, slow growth, and sensitive to stressful environments. To conserve wild species and to meet the demands for medicinal plant materials, new technologies for $A$. formosanus plant production with great biomass and high quality are required.

In 2000, a new concept for the production of transplants in a controlled environment was introduced (Kozai et al., 2000). In this system, artificial light is the sole light source for plant growth; photosynthetic photon flux $(P P F), \mathrm{CO}_{2}$ concentration, air temperature, relative humidity, and air speed are well controlled for optimizing plant productivity and quality. The major advantages of growing plants under controlled environments are maximization of plant biomass, consistency, and quality. Environmental factors also have remarkable effects on secondary metabolite biosynthesis. The secondary metabolites are defined as bioactive molecules, which provide the plant with defense mechanisms to survive from herbivores, environmental stresses, disease, or competition and may affect the growth and development of other organisms (Seigler, 1996). Quality of medicinal plants is determined by their superior genetic characteristics and great biomass with high and consistent secondary metabolite content (Kozai, 2005). High-quality medicinal plants can be produced only under carefully controlled environments (Afreen et al., 2005). Therefore, growing plants under a controlled environment can be considered an alternative way for medicinal plant production to ensure safety and efficacy.

A number of earlier investigations have reported that environmental factors such as light intensity can significantly improve growth and alter the metabolite concentrations. For example, the increasing light intensity at a $P P F$ of $100 \mu \mathrm{mol} \cdot \mathrm{m}^{-2} \cdot \mathrm{s}^{-1}$ significantly improved the growth and photosynthetic capability of in vitro Momordica grosvenori plantlets (Zhang et al., 2009). Briskin and Gawienowski (2001) reported that growing St. John's wort plants at a $P P F$ of $400 \mu \mathrm{mol} \cdot \mathrm{m}^{-2} \cdot \mathrm{s}^{-1}$ significantly increased the hypericin concentration with enhanced photosynthetic activity. Light is also involved in regulating antioxidant enzymes and secondary metabolites. Mohammad et al. (2005) found that micropropagated Phalaenopsis plantlets had higher superoxide dismutase (SOD) content to adapt the increasing light intensity. Zhong et al. (1991) successfully increased anthocyanin production in cell culture of Perilla frutescens (shiso) by increasing light intensity.

However, there is little information about the effects of light intensity on growth and secondary metabolite of $A$. formosanus. Therefore, the objective of this study was to determine the effects of light intensity on the growth, photosynthetic capability, and total flavonoid accumulation of $A$. formosanus plants in a controlled environment.

\section{Materials and Methods}

Plant material, treatments, and culture conditions. Anoectochilus formosanus plantlets were cultured in vitro for $30 \mathrm{~d}$ and acclimated ex vitro for $10 \mathrm{~d}$. The acclimated plantlets, each with four or five unfolded leaves, were used in this study. The average leaf area, 
fresh and dry weight, and stem length per plant were $764 \pm 16 \mathrm{~mm}^{2}, 821 \pm 17.3 \mathrm{mg}, 78 \pm$ $2.6 \mathrm{mg}$, and $6.98 \pm 0.09 \mathrm{~cm}$, respectively. The plants were transplanted into a plastic tray $(540 \times 270 \times 50 \mathrm{~mm})$ containing vermiculite and peatmoss (Growing Mix I; Fafard Co., Ltd., Inkerman, Canada) in a 1:2 ratio by volume and placed in a growth chamber $(2.3 \mathrm{~m}$ in length, $1.8 \mathrm{~m}$ in width, $1.4 \mathrm{~m}$ in height, Zhejiang Qunxin Biological Industry Development Co., Ltd., Jiaxing, China). The experiment included four treatments, $\mathrm{L}_{10}, \mathrm{~L}_{30}, \mathrm{~L}_{60}$, and $\mathrm{L}_{90}$, in which $\mathrm{L}$ indicates light intensity and subscripts denote $P P F$. Light intensity was measured on the surface of the empty shelves with a light meter (Model LI-250A; LI-COR, Lincoln, NE).

The air temperature and relative humidity in the growth chamber were maintained at $25 \pm 1{ }^{\circ} \mathrm{C}$ and $80 \% \pm 5 \%$, respectively. The photoperiod was $14 \mathrm{~h}$ per day supplied with cool-white fluorescent lamps. The $\mathrm{CO}_{2}$ concentration was maintained at $1000 \mu \mathrm{mol} \cdot \mathrm{mol}^{-1}$ in the growth chamber. The $\mathrm{CO}_{2}$ concentration was measured and controlled by a $\mathrm{CO}_{2}$ controller with a nondispersive infrared detector $\mathrm{CO}_{2}$ sensor (T6004; Telaire Co., Ltd., Shoreview, MN). Seventy-two replications (72 plants) were used for each treatment. The experiment was conducted twice.

Measurements, calculation, and statistical analysis. The plants were harvested on Day 45 for destructive measurements and analysis. Plant growth, chlorophyll concentration and fluorescence, SOD activity, and total flavonoid concentration were measured. Leaf area was determined using image and quantify analysis software (LIA32 for Windows 95; K. Yamamoto, Nagoya, Japan) with an image scanner. Dry weight of the plants was determined after oven-drying at $80{ }^{\circ} \mathrm{C}$ for $72 \mathrm{~h}$.

For chlorophyll measurement, the second and third fully expanded leaves from the apex were cut into pieces, soaked in $5 \mathrm{~mL} \mathrm{~N}, \mathrm{~N}$ dimethylformamide solution, and shaken once every $10 \mathrm{~min}$ for $2 \mathrm{~h}$ at $4{ }^{\circ} \mathrm{C}$ (Moran and Porath, 1980). Absorbance was measured with an ultraviolet-vis spectrophotometer (Helios Gamma; Thermo Spectronic Co., Ltd., Cambridge, UK) at wavelengths of $664 \mathrm{~nm}, 647$ $\mathrm{nm}$, and $603 \mathrm{~nm}$. The chlorophyll concentration, including chlorophyll a and chlorophyll $\mathrm{b}$, was determined on a fresh weight basis $\left(\mu \mathrm{g} \cdot \mathrm{g}^{-1}\right)$ and calculated using the formula of Moran (1982).

The ratio of variable to maximum chlorophyll fluorescence $\left(\mathrm{F}_{\mathrm{v}} / \mathrm{F}_{\mathrm{m}}\right)$ and electron transport rate (ETR) were measured and calculated with a Maxi-Imaging-PAM chlorophyll fluorescence measuring system (Walz, Effeltrich, Germany). After $43 \mathrm{~d}$ of culture, the second and third fully expanded leaves (counted down from apex) were used for the measurement. Six replications or six leaves were measured in each treatment. For chlorophyll fluorescence measurement, the plants were placed in a dark room to adapt for $15 \mathrm{~min}$. Next, randomly chosen intact leaves from four treatments were placed in the measuring head $(10 \times 13 \mathrm{~cm})$ to measure the $\mathrm{F}_{\mathrm{v}} / \mathrm{F}_{\mathrm{m}}$. The leaves without dark adaptation were used to evaluate ETRs. Each ETR value was obtained using actinic irradi- ance for $10 \mathrm{~s}$. All relevant fluorescence parameters, including actinic irradiance and leaf temperature, were recorded and ETRs were calculated in the Maxi-Imaging-PAM system.

The extraction and activity analysis of SOD were performed by using the method described by Rao and Sresty (2000). In brief, the $0.5 \mathrm{~g}$ leaves were ground with $5 \mathrm{~mL}$ icecold $0.05 \mathrm{~mol} / \mathrm{L}$ phosphate buffer $(\mathrm{pH} 7.8)$. The homogenates were centrifuged at $4{ }^{\circ} \mathrm{C}$ for $20 \mathrm{~min}$ at $12,000 \times g$ and the resulting supernatants were used for determination of enzyme activity. SOD activity was assayed by measuring its ability to inhibit the photochemical reduction of nitroblue tetrazolium (NBT). The $3-\mathrm{mL}$ reaction mixture contained $1.5 \mathrm{~mL}$ phosphate buffer ( $\mathrm{pH} 7.8$ ), $13 \mu \mathrm{M}$ methionine, $75 \mu \mathrm{M}$ NBT, $2 \mu \mathrm{M}$ riboflavin, $10 \mu \mathrm{M}$ EDTA-Na ${ }_{2}$, and $50 \mu \mathrm{L}$ of enzyme extract. The reaction was initiated by exposing the tubes to $4000 \mathrm{~lx}$ light intensity for $20 \mathrm{~min}$. A nonirradiated complete reaction mixture served as a blank and another complete reaction mixture without enzyme, which gave the maximal blue color, served as a control. The reaction was stopped by quenching the irradiation light, and then the tubes were covered with a black cloth waiting for testing. The absorbance was recorded at $560 \mathrm{~nm}$ by the ultraviolet-vis spectrophotometer and one unit of SOD was defined as the amount of enzyme required to result in a $50 \%$ inhibition of the rate of NBT reduction.

Total flavonoid concentration in the leaves of plants grown at different light intensities was measured following the method of Sakanaka et al. (2005). The reaction contained $0.25 \mathrm{~mL}$ of the methanolic plant extract or (+)-catechin standard solution and $1.25 \mathrm{~mL}$ of distilled water followed by the addition of $0.75 \mathrm{~mL} 5 \%$ sodium nitrite solution. After $6 \mathrm{~min}, 0.15 \mathrm{~mL}$ of $10 \%$ aluminum chloride solution was added and the mixture was allowed to stand $5 \mathrm{~min}$ and then $0.5 \mathrm{~mL}$ of $1 \mathrm{M}$ sodium hydroxide was added. The mixture was brought to $2.5 \mathrm{~mL}$ with distilled water and mixed well. The absorbance was measured immediately at $510 \mathrm{~nm}$. The data were calculated using $(+)$-catechin for total flavonoid concentration.

Statistical significance was determined by one-way analysis of variance using Sigma Stat (SigmaStat $^{\mathrm{TM}}$ for Windows Version 2.03; SPSS Inc., Chicago. IL). Differences among means were assessed with the Holm-Sidak test and a significance level of $P \leq 0.05$.

\section{Results}

Plant growth. The results of plant growth with different light intensities on Day 45 are summarized in Table 1 and Figure 1. Among all treatments, the plant growth was greatest in the $\mathrm{L}_{30}$ treatment followed by $\mathrm{L}_{60}$. Leaf area, stem length, and fresh weight were $1.4,1.1$, and 1.3 times greater, respectively, in the $\mathrm{L}_{30}$ than those in the $\mathrm{L}_{90}$. Dry weight was 1.4 times greater in the $\mathrm{L}_{30}$ than that in the $\mathrm{L}_{10}$. There was no significant difference in dry weight between $\mathrm{L}_{60}$ and $\mathrm{L}_{90}$ treatments. An increase

Table 1. Effects of four levels of light intensity on the growth of Anoectochilus formosanus per plant grown for $45 \mathrm{~d}$ under a controlled environment.

\begin{tabular}{lccrcr}
\hline & & \multicolumn{3}{c}{ Plant weight $(\mathrm{mg})$} \\
\cline { 4 - 6 } Treatment & Leaf area $\left(\mathrm{mm}^{2}\right)$ & Stem length $(\mathrm{cm})$ & \multicolumn{1}{c}{ Fresh } & \multicolumn{1}{c}{ Dry } & DW/FW $(\%)$ \\
\hline $\mathrm{L}_{10}{ }^{\mathrm{z}}$ & $963 \pm 16 \mathrm{~b}^{\mathrm{y}}$ & $8.26 \pm 0.10 \mathrm{~b}$ & $995 \pm 13 \mathrm{c}$ & $103 \pm 1.3 \mathrm{c}$ & 10.4 \\
$\mathrm{~L}_{30}$ & $1167 \pm 22 \mathrm{a}$ & $8.57 \pm 0.06 \mathrm{a}$ & $1184 \pm 22 \mathrm{a}$ & $140 \pm 2.7 \mathrm{a}$ & 11.8 \\
$\mathrm{~L}_{60}$ & $986 \pm 15 \mathrm{~b}$ & $7.97 \pm 0.08 \mathrm{c}$ & $1043 \pm 20 \mathrm{~b}$ & $126 \pm 2.4 \mathrm{~b}$ & 12.1 \\
$\mathrm{~L}_{90}$ & $850 \pm 19 \mathrm{c}$ & $7.90 \pm 0.07 \mathrm{c}$ & $936 \pm 13 \mathrm{~d}$ & $121 \pm 1.5 \mathrm{~b}$ & 12.9 \\
\hline
\end{tabular}

${ }^{\mathrm{z}} \mathrm{L}_{10}, \mathrm{~L}_{30}, \mathrm{~L}_{60}$, and $\mathrm{L}_{90}$ were four light intensity treatments, in which $\mathrm{L}$ indicates light intensity and subscripts denote photosynthetic photon flux density.

${ }^{\mathrm{y}}$ Data are mean $\pm \mathrm{SE}$, and means denoted by the same letter in a column were not significantly different $(P \leq$ $0.05)$.

$\mathrm{DW} / \mathrm{FW}=$ dry weight/fresh weight.

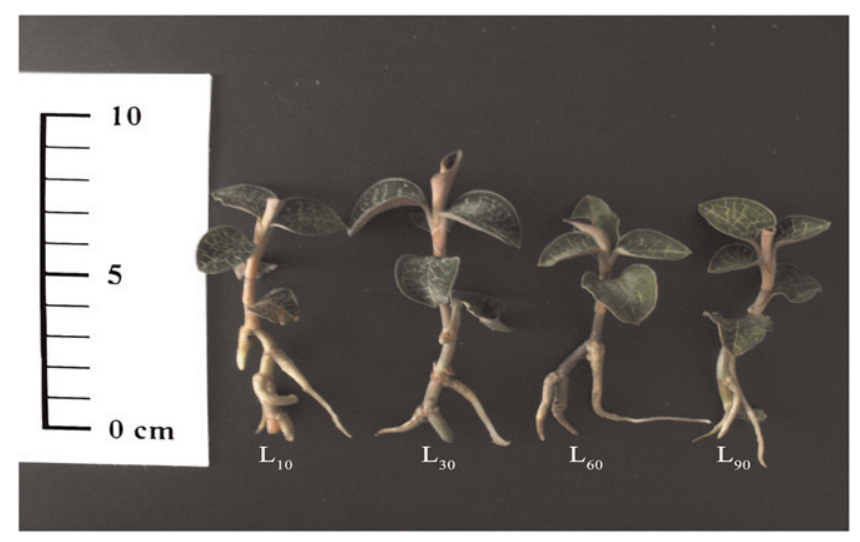

Fig. 1. Anoectochilus formosanus grown under controlled environment with four levels of light intensity, $10,30,60$, or $90 \mu \mathrm{mol} \cdot \mathrm{m}^{-2} \cdot \mathrm{s}^{-1}$, for $45 \mathrm{~d} \cdot \mathrm{L}_{10}, \mathrm{~L}_{30}, \mathrm{~L}_{60}$, and $\mathrm{L}_{90}$ were four light intensity treatments, in which $\mathrm{L}$ indicates light intensity and subscripts denote photosynthetic photon flux $(P P F)$. 
in light intensity increased the ratio of dry weight to fresh weight of plant (DW/FW).

The plants cultured in the $\mathrm{L}_{10}$ treatment not only had lowest dry weight, but also had lowest ratio of DW/FW. The plants cultured in the $\mathrm{L}_{90}$ treatment had the highest ratio of DW/FW, but the thickset stem, and small, thick, and yellow leaves were observed in the $\mathrm{L}_{90}$ treatments (Fig. 1).

Chlorophyll concentration and chlorophyll $a / b$ ratio. The chlorophyll concentration of plants was significantly influenced by the different light intensities. Among all treatments, the chlorophyll concentration was greatest in the $L_{10}$ treatment and then decreased consistently as the light intensified, lowest in the $\mathrm{L}_{90}$ treatment (Fig. 2). In contrast, the ratio of chlorophyll a to chlorophyll $b$ increased to a maximum (3.72) as the light intensified to a $P P F$ of $60 \mu \mathrm{mol} \cdot \mathrm{m}^{-2} \cdot \mathrm{s}^{-1}$ and then decreased to 3.67 at a $P P F$ of 90 $\mu \mathrm{mol} \cdot \mathrm{m}^{-2} \cdot \mathrm{s}^{-1}$, creating a parabola.

Ratio of Variable to Maximum Chlorophyll Fluorescence and Electron Transport Rate. The $\mathrm{F}_{\mathrm{v}} / \mathrm{F}_{\mathrm{m}}$ ratio, reflecting the maximal photochemical efficiency of photosystem II (PSII), is usually steady with fluctuations from 0.75 to 0.85 for nonstressed plants (BolharNordenkampf et al., 1989). In our present study, the $\mathrm{F}_{\mathrm{v}} / \mathrm{F}_{\mathrm{m}}$ (determined using the second or third leaf from the apex) ranged from 0.75 to 0.81 , except for the $\mathrm{L}_{90}$, which had an abnormal ratio (0.36) in the second leaf. Probably, photoinhibition had occurred in the second leaf taken from the $\mathrm{L}_{90}$ treatment and consequently it had the lowest ETR (Fig. 3A).

The ETRs of leaves including the second and third leaves were highest in the $\mathrm{L}_{30}$ treatment followed by the $\mathrm{L}_{60}$. The ETRs were, respectively, lowest in the $\mathrm{L}_{90}$ treatment for the second leaf and the $\mathrm{L}_{10}$ for third leaf (Fig. $3)$. Moreover, the maximum ETR for all treatments was at a $P P F$ of $35 \mu \mathrm{mol} \cdot \mathrm{m}^{-2} \cdot \mathrm{s}^{-1}$ in the second leaf and a $P P F$ of $55 \mu \mathrm{mol} \cdot \mathrm{m}^{-2} \cdot \mathrm{s}^{-1}$ in the third leaf.

Superoxide dismutase activity and total flavonoid content. Increase in light intensity from 10 to $60 \mu \mathrm{mol} \cdot \mathrm{m}^{-2} \cdot \mathrm{s}^{-1}$ resulted in a significant increasing SOD activity (Fig. 4). SOD activity in the $\mathrm{L}_{60}$ treatment was 2.3 times higher than that in the $\mathrm{L}_{10}$. However, SOD activity decreased as light intensity increased to $\mathrm{L}_{90}$.

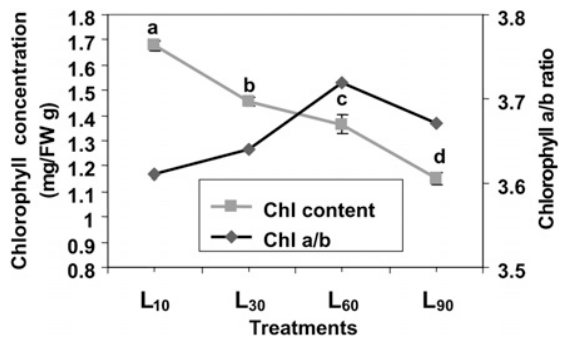

Fig. 2. Effects of four levels of light intensity, 10,30 60 , or $90 \mu \mathrm{mol} \cdot \mathrm{m}^{-2} \cdot \mathrm{s}^{-1}$, on the chlorophyll concentration and chlorophyll $\mathrm{a} / \mathrm{b}$ ratio of Anoectochilus formosanus plants. $\mathrm{L}_{10}, \mathrm{~L}_{30}, \mathrm{~L}_{60}$, and $\mathrm{L}_{90}$ were four light intensity treatments, in which $\mathrm{L}$ indicates light intensity and subscripts denote photosynthetic photon flux $(P P F)$. Vertical bars represent SE.
Similarly, as the light intensity increased from 10 to $60 \mu \mathrm{mol} \cdot \mathrm{m}^{-2} \cdot \mathrm{s}^{-1}$, the total flavonoid concentration of the plant increased to the highest in the $\mathrm{L}_{60}$ treatment, but then significantly decreased to the lowest in the $\mathrm{L}_{90}$ (Fig. 5 ). The total flavonoid concentration of the $L_{60}$ plant was 1.3 times greater than that of the $\mathrm{L}_{90}$ plant.

\section{Discussion}

Plant growth and photosynthetic capability. Light intensity is one of the key environmental factors influencing plant growth. The results clearly showed that $A$. formosanus plants grown under $\mathrm{L}_{30}$ achieved a great biomass with largest leaf area and longest stem length among all treatments (Table 1; Fig. 5). Chen et al. (1994) reported that the light saturation point of Anoectochilus was $\approx 60 \mu \mathrm{mol} \cdot \mathrm{m}^{-2} \cdot \mathrm{s}^{-1}$, indicating Anoectochilus is a typical shade plant. Moreover, a light intensity either too low or too high would not be suitable to growth of $A$. formosanus plants. In the present study, the plant grown under $\mathrm{L}_{10}$ and $\mathrm{L}_{90}$ had lower biomass and smaller leaf area. The low biomass of plants has frequently been explained by low photosynthetic ability. The low photosynthesis can result in low growth rate. ETRs allow for the rapid and noninvasive assessment of light response of PSII and are used to study the photosynthetic performance and photoacclimation of photosynthetic organisms. The maximum ETR was related to the maximum photosynthetic capability, which was obtained when the photosynthetic rate was limited by the
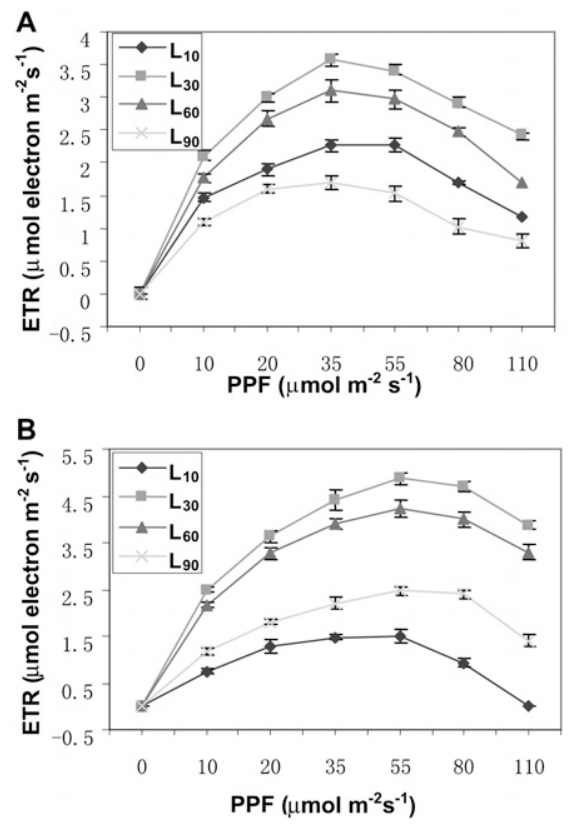

Fig. 3. The rapid light curves of Anoectochilus formosanus plants (A) for the second leaves and (B) for the third leaves from the apex of the shoot at four levels of light intensity, 10,30,60, or $90 \mu \mathrm{mol} \cdot \mathrm{m}^{-2} \cdot \mathrm{s}^{-1}$ on Day $45 . \mathrm{L}_{10}, \mathrm{~L}_{30}, \mathrm{~L}_{60}$, and $\mathrm{L}_{90}$ were four light intensity treatments, in which L indicates light intensity and subscripts denote photosynthetic photon flux $(P P F)$. Vertical bars represent SE. activity of the electron transport chain or Calvin cycle enzymes (Behrenfeld et al., 2004; Ralph et al., 2005). As shown in Figure 3 , the $\mathrm{L}_{30}$ plants had the highest ETRs, which contributed to a great dry weight. The $\mathrm{L}_{10}$ and $\mathrm{L}_{90}$ plants, however, had the lowest ETRs in the third and second leaves, respectively, which contributed to low dry weight in both treatments

Photoinhibition may occur when light intensity exceeds what is required for the saturation of photosynthesis. The decline in $\mathrm{F}_{\mathrm{v}} / \mathrm{F}_{\mathrm{m}}$ represents the accumulation of a photodamaged PSII center (Rosenqvist and Kooten, 2003). In our study, the decline in $F_{v} / F_{m}$ was observed in the second leaves of the $\mathrm{L}_{90}$ plants $\left(\mathrm{F}_{\mathrm{v}} / \mathrm{F}_{\mathrm{m}}=0.36\right)$. The $90 \mu \mathrm{mol} \cdot \mathrm{m}^{-2} \cdot \mathrm{s}^{-1}\left(\mathrm{~L}_{90}\right)$ probably exceeded the photoprotective capacity of the plants and resulted in photodamage. This adverse phenomenon can manifest as a loss of PSII activity (Masuda et al., 2002). A loss in the reaction-center content of PSII was associated with a slower ETR (Pell et al., 1994). Thus, the photoinhibition could account for the lower capacity of ETR as shown in the leaf from the $\mathrm{L}_{90}$ treatment in our study. Vasilikiotis and Melis (1994) also reported that in photoinhibition, the chloroplasts contained much of the same amount of PSII as they did under low light intensity. However,



Fig. 4. Effects of four levels of light intensity, 10, 30, 60 , or $90 \mu \mathrm{mol} \cdot \mathrm{m}^{-2} \cdot \mathrm{s}^{-1}$, on the superoxide dismutase (SOD) activity of Anoectochilus formosanus plants. $\mathrm{L}_{10}, \mathrm{~L}_{30}, \mathrm{~L}_{60}$, and $\mathrm{L}_{90}$ were four light intensity treatments, in which $\mathrm{L}$ indicates light intensity and subscripts denote photosynthetic photon flux $(P P F)$. Vertical bars represent SE.



Fig. 5. The total flavonoid concentration of Anoectochilus formosanus plants at four levels of light intensity, $10,30,60$, or $90 \mu \mathrm{mol} \cdot \mathrm{m}^{-2} \cdot \mathrm{s}^{-1}$, on Day 45. $\mathrm{L}_{10}, \mathrm{~L}_{30}, \mathrm{~L}_{60}$, and $\mathrm{L}_{90}$ were four light intensity treatments, in which $\mathrm{L}$ indicates light intensity and subscripts denote photosynthetic photon flux $(P P F)$ density. Vertical bars represent SE. 
up to $\approx 80 \%$ of PSII were photochemically inactive because of photodamage. This is the reason why the $\mathrm{L}_{10}$ plant with low light intensity and the $\mathrm{L}_{90}$ plant with photoinhibition had low ETRs and resulted in low carbohydrate accumulation in both treatments. In the present study, we also found that the ETRs in the second leaves from the $\mathrm{L}_{90}$ treatment were lower than those from the $\mathrm{L}_{10}$. In contrast, the ETRs in the third leaves from the $\mathrm{L}_{90}$ were higher than those from the $\mathrm{L}_{10}$. The phenomenon can be explained by the fact that the upper leaves may create a dense canopy to protect lower ones from photodamage during plant growth. Thus, the dry weight of plants from the $\mathrm{L}_{90}$ treatment was greater than that from $\mathrm{L}_{10}$.

Although the decline in $F_{v} / F_{m}$ was not observed in the leaves of the $\mathrm{L}_{60}$ plants, it could be assumed that the $\mathrm{L}_{60}$ plants also probably had little light stress resulting from lower ETRs compared with the $\mathrm{L}_{30}$ plants. Moreover, as shown in Figure 3, the $P P F$ for the maximum photosynthetic capability of A. formosanus plants in all the treatments was $35 \mu \mathrm{mol} \cdot \mathrm{m}^{-2} \cdot \mathrm{s}^{-1}$ in the second leaf and 55 $\mu \mathrm{mol} \cdot \mathrm{m}^{-2} \cdot \mathrm{s}^{-1}$ in the third leaf. We therefore suggest that $P P F$ of 30 to $50 \mu \mathrm{mol} \cdot \mathrm{m}^{-2} \cdot \mathrm{s}^{-1}$ would be suitable for growth of $A$. formosanus plants.

Chlorophyll concentration. The chlorophyll concentration of plants plays an important role in the absorption of light during photosynthesis. In the present study, low light intensity significantly enhanced chlorophyll concentration of plants, and the chlorophyll concentration decreased as the light intensity increased. The greatest chlorophyll concentration was estimated at a lowest $P P F$ of $10 \mu \mathrm{mol} \cdot \mathrm{m}^{-2} \cdot \mathrm{s}^{-1}$. The results agree with the finding of Walters et al. (2003) that leaves of plants growing at low $P P F$ have relatively higher contents of chloroplastic pigments, electron carriers, and increased number of chloroplast. The result also demonstrates that plants could balance light absorption and translation by regulating chlorophyll synthesis (Bailey et al., 2001). The change of chlorophyll concentration was possibly an acclimation of plants to different light intensities.

For many plants, changes in light intensity may elicit physiological responses at the level of leaf and chloroplast (Bailey et al., 2001). In our study, the leaf responded to the light intensity by adjusting or reducing the chlorophyll concentration. Chloroplast responded to light intensity by changing chlorophyll $\mathrm{a} / \mathrm{b}$ and adjusting to the ETR. As shown in Figure 2, an increase in light intensity from $\mathrm{L}_{10}$ to $\mathrm{L}_{60}$ was associated with an increase in chlorophyll $a / b$ and a decrease in the size of the PSII light-harvesting antenna (Bailey et al., 2001; Masuda et al., 2002). Thus, interconversion of chlorophyll a and chlorophyll $\mathrm{b}$ is significant for the establishment of required chlorophyll $\mathrm{a} / \mathrm{b}$ ratio during the adaption of leaves to high and low light intensity (Ito et al., 1993).

Superoxide dismutase activity. SOD is an important enzyme, which contributed to clear up superoxide in plants in the case of light stress, and SOD activity can give us some valuable information whether the plant was stressed by high light. Plants can fix carbon and photosynthesize by absorbing light energy at a proper light intensity. Excess light absorption resulted in acidic chloroplast lumen, reduced electron transport chain, and excess excitation energy (EEE) within chloroplast (Powles, 1984). EEE is toxic for plants by producing singlet oxygen, which can cause photoinhibition mainly resulting from oxidative damage to the PSII. Depletion of the $\mathrm{NADP}^{+}$pool under EEE causes an increase in the rate of electron flow from the donor side of PSI to oxygen, generating reactive oxygen species (ROS) such as superoxide and hydrogen peroxide (Asada, 1999). If these ROS are not removed immediately, they can easily cause damage to the cellular and molecular machinery, protein modification, and lipid peroxidation. Plants have evolved various antioxidative enzymes to avoid damage. SOD is an important antioxidative enzyme, which contributes to clear up superoxide in plants. In the present study, increasing light intensity from 10 to $60 \mu \mathrm{mol} \cdot \mathrm{m}^{-2} \cdot \mathrm{s}^{-1}$ increased SOD activity, which suggested SOD plays an important role against the ROS caused by light stress. However, when light intensity reached 90 $\mu \mathrm{mol} \cdot \mathrm{m}^{-2} \cdot \mathrm{s}^{-1}$, SOD activity was found inversely, which probably related to the susceptibility of the plant to photodamage or to a higher temperature around the plants under high light intensity. Similarly, Rabinowitch (1980) found that in scorching conditions, SOD activity decreased; without scorching, SOD activity should increase.

Total flavonoid content. The production of total flavonoid content can be explained by the interaction of oxidative stress and photosynthesis. It is widely believed that the synthesis of secondary metabolites in plants is part of the defense responses of plants to oxidative stress. A number of earlier investigations have suggested that oxidative stress plays an important role for the synthesis of secondary metabolite in plant growth (Wojtaszek, 2002). In our study, as the light intensity increased from 10 to $60 \mu \mathrm{mol} \cdot \mathrm{m}^{-2} \cdot \mathrm{s}^{-1}$, the SOD activity increased along with an increase in the total flavonoid concentration. The greatest total flavonoid concentration found in the $\mathrm{L}_{60}$ plants may be the result of the increased ROS induced by oxidative stress. The secondary metabolite synthesis of plants requires endogenous signal components such as ROS (Menke et al., 1999). ROS can function as a signal for the induction of defense systems and could enhance secondary metabolite production (Berglund and Ohlsson, 1995). This enables the plants to protect them against oxidative stress (Scalet et al., 1995).

Meanwhile, for many carbon-based metabolites, several hypotheses have been developed to explain phenotypic and evolutionary patterns in the distribution of plant secondary metabolites (Heyworth et al., 1998). For example, according to the "overflow metabolism" concept, when carbon production exceeds the carbon demand associated with plant growth, the excess carbon is channeled into biosynthesis of secondary metabolites (Matsuki, 1996). In the present study, the total flavonoid concentration $\left(\mathrm{mg} \cdot \mathrm{g}^{-1} \mathrm{DW}\right)$ in the $\mathrm{L}_{30}$ plants was lower than that of the $\mathrm{L}_{60}$ plants. However, the total flavonoid content (mg/plant) in the $\mathrm{L}_{30}$ plants was higher than that of the $\mathrm{L}_{60}$ plants as a result of a higher dry mass or enhanced photosynthesis. The total flavonoid concentration significantly decreased in the $\mathrm{L}_{90}$ plants can be explained by low photosynthesis resulting from photoinhibition and synthesis mechanical damage. Further study is required to better understand the relationship among photosynthesis, oxidative stress, and secondary metabolite contents in $A$. formosanus plants.

\section{Conclusion}

To summarize, $A$. formosanus is a typical shade plant suitable to grow under lower intensity of $P P F$ ranging from 30 to 50 $\mu \mathrm{mol} \cdot \mathrm{m}^{-2} \cdot \mathrm{s}^{-1}$ for both growth and production of total flavonoid content. Higher light intensity such as a $P P F$ of $90 \mu \mathrm{mol} \cdot \mathrm{m}^{-2} \cdot \mathrm{s}^{-1}$ induced stress on plant growth and reduced photosynthetic capability and the flavonoid accumulation. The production of $A$. formosanus plants with high total flavonoid content under a controlled environment can be further increased by optimizing other environmental parameters such as light quality, photoperiod, temperature, and relative humidity and by optimizing the nutrient composition. Such studies are currently underway in our laboratory. Therefore, growing plants in a controlled environment can be considered a good alternative way of producing highquality $A$. formosanus to meet the demand for its medicinal use. We are hopeful that application of a controlled environment with the optimization of environmental factors will be an efficient method for producing A. formosanus plants with great biomass and high secondary metabolite.

\section{Literature Cited}

Afreen, F., S.M.A. Zobayed, and T. Kozai. 2005. Spectral quality and UV-B stress stimulate glycyrrhizin concentration of Glycyrrhiza uralensis in hydroponic and pot system. Plant Physiol. Biochem. 43:1074-1081.

Asada, K. 1999. The water-water cycle in chloroplasts: Scavenging of active oxygen and dissipation of excess photons. Annu. Rev. Plant Physiol. Plant Mol. Biol. 50:601-639.

Asahishinbun. 1997. Asahi Encyclopedia the World of Plants, Vol. 9. Asahishinbun Press, Tokyo, Japan. p. 243-244.

Bailey, S., R.G. Walters, and S.J.P. Horton. 2001. Acclimatization of Arabidopsis thaliana to the light environment: The existence of separate low light and high light responses. Planta 213: 794-801.

Behrenfeld, M.J., O. Prasil, M. Babin, and F. Bruyant. 2004. In search of a physiological basis for covariations in light-limited and lightsaturated photosynthesis. J. Phycol. 40:4-25.

Berglund, T. and A.B. Ohlsson. 1995. Defensive and secondary metabolism in plant tissue cultures, with special reference to nicotinamide, glutathione and oxidative stress. Plant Cell Tissue Organ Cult. 43:137-145.

Bolhar-Nordenkampf, H.R., S.P. Long, N.R. Baker, G. Oquist, U. Schreiber, and E.G. Lechner. 
1989. Chlorophyll fluorescence as a probe of the photosynthetic competence of leaves in the field: A review of current instrumentation. Funct. Ecol. 3:497-514.

Briskin, D.P. and M.C. Gawienowski. 2001. Differential effects of light and nitrogen on production of hypericins and leaf glands in Hypericum perforatum. Plant Physiol. Biochem. 39:1075-1081.

Chen, Y., K. Lin, Q. Guan, and J. Chen. 1994. Biological characteristics and habitat characters of Anoectochilus roxburghii [in Chinese]. Subtrop. Plant Res. Commun. 23:18-24.

Heyworth, C.J., G.R. Iason, V. Temperton, P.G. Jarvis, and A.J. Duncan. 1998. The effect of elevated $\mathrm{CO}_{2}$ concentration and nutrient supply on carbon based plant secondary metabolites in Pinus sylvestris L. Oecologia 115: 344-350.

Ito, H., Y. Tanaka, H. Tsuji, and A. Tanaka. 1993. Conversion of chlorophyll $\mathrm{b}$ to chlorophyll $\mathrm{a}$ in isolated cucumber etioplast. Arch. Biochem. Biophys. 306:148-151.

Kan, W.S. 1986. Pharmaceutical botany, p. 647. National Research Institute of Chinese Medicine, Taiwan.

Kozai, T. 2005. Introduction, p. 1-5. In: Kozai, T., F. Afreen, and S.M.A. Zobayed (eds.). Photoautotrophic (sugar-free medium) micropropagation as a new propagation and transplant production system. Springer Academic Publisher, Dordrecht, The Netherlands.

Kozai, T., C. Kubota, C. Chun, F. Afreen, and K. Ohyama. 2000. Necessity and concept of the closed transplant production system, p. 3-19. In: Kubota, C. and C. Chun (eds.). Proc. for the International Symposium on Transplant Production in Closed System. Kluwer Academic Publisher, Dordrecht, The Netherlands.

Masuda, T., J.E.W. Polle, and A. Melis. 2002. Biosynthesis and distribution of chlorophyll among the photosystems during recovery of the green alga Dunaliella salina from irradiance stress. Plant Physiol. 128:603-614.
Matsuki, M. 1996. Regulation of plant phenolic synthesis: From biochemistry to ecology and evolution. Aust. J. Bot. 44:613-634.

Menke, F.L., S. Parchmann, M.J. Mueller, J.W Kijne, and J. Memelink. 1999. Involvement of the octadecanoid pathway and protein phosphorylation in fungal elicitor-induced expression of terpenoid indole alkaloid biosynthetic genes in Catharanthus roseus. Plant Physiol. 19:1289-1296.

Mohammad, B.A., E.J. Hahn, and K.Y. Paek. 2005. Effect of light intensities on antioxidant enzymes and malondialdehyde content during short-term acclimatization on micropropagated Phalaenopsis plantlet. Environ. Exp. Bot. 54: 109-120.

Moran, R. 1982. Formulae for determination of chlorophyllous pigments extracted with N, Ndime-thylformamide. Plant Physiol. 69:13761381.

Moran, R. and D. Porath. 1980. Chlorophyll determination in intact tissues using N, N-dimethylformamide. Plant Physiol. 65:478-479.

Pell, E.J., N.A. Eckardt, and R.E. Glick. 1994. Biochemical and molecular basis for impairment of photosynthetic potential. Photosynth. Res. 39:453-462.

Powles, S.B. 1984. Photoinhibition of photosynthesis induced by visible light. Annu. Rev Plant Physiol. 124:17-20.

Rabinowitch, H.D. 1980. Skland: Superoxide dismutase: A possible protect agent against sunscold in tomatoes. Planta 148:162-167.

Ralph, P.J., A. MacMinn, K.G. Ryan, and C. Ashworth. 2005. Short-term effect of temperature on the photokinetics of micro-algae from the surface layers of Antarctic ice. J. Phycol. 41:763-769.

Rao, K.V.M. and T.V.S. Sresty. 2000. Antioxidant parameters in the seedlings of pigeon pea [Cajanus cajan (L.) Millspaugh] in response to $\mathrm{Zn}$ and Ni stresses. Plant Sci. 157:113-128.

Rosenqvist, E. and V. Kooten. 2003. Chlorophyll fluorescence: A general description and no- menclature, p. 32-77. In: DeEll, J.R. and P.M.A. Toivonen (eds.). Practical applications of chlorophyll fluorescence in plant biology. Kluwer Academic Publisher, Dordrecht, The Netherlands.

Sakanaka, S., Y. Tachibana, and Y. Okada. 2005. Preparation and antioxidant properties of extracts of Japanese persimmon leaf tea (Kakinoha-cha). Food Chem. 89:569-575.

Scalet, M., R. Federice, M.C. Guido, and F. Manes 1995. Peroxidase activity and polyamine changes in response to ozone and stimulated acid rain in Aleppo pine needles. Environ. Exp. Bot. 35:417-425.

Seigler, D.S. 1996. Chemistry and mechanisms of allelopathic interactions. Agron. J. 88:876-885.

Shih, C.C., Y.W. Wu, and W.C. Lin. 2003. Scavenging of reactive oxygen species and inhibition of the oxidation of low density lipoprotein by the aqueous extraction of Anoectochilus formosanus. Am. J. Chin. 31:25-36.

Takatsuki, S., J.D. Wang, and T. Narui. 1992. Studies on the components of crude drug 'kim-soan-lian.' J. Jap. Botany 67:121-123.

Vasilikiotis, C. and A. Melis. 1994. Photosystem II reaction center damage and repair cycle: Chloroplast acclimatization strategy to irradiance stress. Proc. Natl. Acad. Sci. USA 91:7222-7226.

Walters, R.G., F. Shephard, J.J.M. Rogers, S.A. Rolfe, and P. Horton. 2003. Identification of mutants of Arabidopsis defective in acclimation of photosynthesis to the light environment. Plant Physiol. 131:472-481.

Wojtaszek, P. 2002. Oxidative stress, antioxidant tolerance. Trends Plant Sci. 9:405-410.

Zhang, M., D. Zhao, Z. Ma, X. Li, and Y. Xiao. 2009. Growth and photosynthetic capability of Momordica grosvenori plantlets grown photoautotrophically in response to light intensity. HortScience 44:1-7.

Zhong, J.J., T. Seki, S. Kinoshita, and T. Yoshida. 1991. Effect of light irradiation on anthocyanin production by suspended culture of Perilla frutescens. Biotechnol. Bioeng. 38:653-658. 